\title{
Seismic hazard expression in risk assessment
}

\author{
X.-X. Tao ${ }^{1,2}$, Z.-R. Tao ${ }^{2} \&$ P. $\mathrm{Li}^{1}$ \\ ${ }^{1}$ Harbin Institute of Technology, People's Republic of China \\ ${ }^{2}$ Institute of Engineering Mechanics, \\ China Earthquake Administration, People's Republic of China
}

\begin{abstract}
Seismic risk assessment, consisting of seismic hazard analysis and vulnerability evaluation, is really a very comprehensive assessment as the first and fundamental step in the earthquake disaster prevention process. In China, seismic hazards and vulnerabilities of many cities have been assessed in the last dozen years. In general, the assessments are completed separately and are combined together for loss estimation. A contrast in the final estimation is pointed out in this paper. The seismic hazard is expressed as the exceeding or occurring probability of an earthquake action, such as intensity $I$ or acceleration $A$. It is an integrative effect from all earthquakes in surrounding potential source areas with various magnitudes. The vulnerability is expressed by the probabilities of damage states of structures given the earthquake action. The loss is estimated through combining this hazard, vulnerability, and loss rates of all damage states. However, it is impossible that all of the earthquakes occur at the same time, and the high-intensity area can never cover the whole metropolis. To make it clear, a numerical example is presented in the paper. The scenario earthquake method is a solution, which is consistent with the regional seismic environment and is determined from the regional attenuation relationship of ground motion. The caused shaking, damage and loss distribution of population, buildings and infrastructures can be further estimated easily. In this way, the overestimation of loss in metropolis is avoided. A case study is demonstrated in this paper as an example.
\end{abstract}

Keywords: scenario earthquake, seismic hazard, losses evaluation. 


\section{Introduction}

Seismic risk is the possibility or chance of impact to human community due to occurrence of an earthquake, including damage, economic loss, victims and injuries, and the gross of the loss, thus risk statements must be given in quantitative terms, Franz Sauter [1]. It describes the effects and consequences of a devastating earthquake in details to help designers, managers and rescuers plan earthquake prevention and reduction operations. As well known, seismic risk assessment consists of seismic hazard analysis and vulnerability evaluation. In general, the two parts are completed by seismological team and engineering team separately. To combine these two together, seismic hazard expression must be improved, especially for application in financial instrument such as insurance, cat bond. Some suggestions are presented in this paper.

\section{Seismic hazard curve}

In the seismic risk assessment procedure adopted for many cities of China, the expected total loss of buildings in a given time period can be calculated by:

$$
E(L)=\sum_{S} \sum_{k=1}^{5} P_{S}\left(D_{k}\right)\left(L_{S}\left(D_{k}\right)+W_{s}\left(D_{k}\right)\right)
$$

where, $k$ is for the 5 damage states (None, Slight, Moderate, Extensive and Complete); $L_{S}\left(D_{k}\right)$ is the loss of $S^{\text {th }}$ type buildings being in $k^{\text {th }}$ damage state; $W_{S}\left(D_{k}\right)$ is the indoor property loss of $S^{\text {th }}$ type buildings being in $k^{\text {th }}$ damage state; $P_{S}\left(D_{k}\right)$ is the probability of $S^{\text {th }}$ type buildings being in $k^{\text {th }}$ damage state. The former two depend on the corresponding unit cost, unit indoor property and the total construction area of $S^{\text {th }}$ type buildings, and loss ratio of $S^{\text {th }}$ type buildings in $k^{\text {th }}$ damage state. The latter is referred to as the engineering seismic risk, can be described as eq. (2).

$$
P_{S}\left(D_{k}\right)=\sum_{I=6}^{9} P_{S}\left(D_{k} \mid I\right) \cdot P(I)
$$

where, $P_{S}\left(D_{k} \mid I\right)$ is the conditional probability of $S^{\text {th }}$ type buildings being in $k^{\text {th }}$ damage state given intensity $I$, so-called vulnerability of $S^{\text {th }}$ type buildings, which is evaluated from damage experience, analysis of a certain number of buildings and sometimes from results of experiments; $P(I)$ is the possibility of intensity $I$ occurrence, and can be derived from $P(I \geq i)$, so-called seismic hazard. The latter depends on the regional seismic environment and attenuation relationship of ground motion, and is generally referred to as seismic hazard curve. In nature, earthquake intensity is a sequential classified variable, so $P(I \geq i)$ is not really a continuous curve. Of course, intensity $I$ in eq. (2) can be 
substituted with other ground motion parameter $Y$, by this way, the symbol " $\Sigma$ " can be changed into " $\int$ ", then $P(Y>y)$ is a continuous curve. Intensity $I$ is preferred to other parameters for vulnerability evaluation, since matrix of $P_{S}\left(D_{k} \mid I\right)$ is mainly from statistical data of earthquake damages in the past, in which earthquake intensity is an essential parameter.

\section{Seismic hazard underestimation at low intensity range}

In general, $P(I)$ is calculated by:

$$
P(I)=P(I \geq i)-P(I \geq i+1)
$$

However, the result of the subtraction will not be reasonable, if $I$ is low. For example, the result of case study in a region with low seismicity is shown in Table 1 . One can see from the table there must be something wrong, since $P_{50}(\mathrm{I}=$ $3)$ is less than $P_{50}(\mathrm{I}=4)$.

Table 1: $\quad$ The occurring probability of low intensity in 50 years.

\begin{tabular}{|c|c|c|c|c|}
\hline Intensity & III & IV & V & VI \\
\hline$P_{50}(I \geqslant i)$ & 0.9289 & 0.6627 & 0.2855 & 0.0583 \\
\hline$P_{50}(I=i)$ & 0.2662 & 0.3772 & 0.2272 & 0.0533 \\
\hline
\end{tabular}

In nature, $P(I)$ must be a monotone decreasing function, i.e. $P(I)$ must be greater than $P(I+1)$, even if intensity is low. Deal with the procedure of seismic hazard, one can understand that $P(I \geqslant i)$ is contributed by earthquakes in many potential source areas with various magnitudes and various occurring times. It means that $P(I \geqslant i)$ consists of not only $P(I=i)$ and $P(I \geq I+1)$, but also $P(I=i$ and $I>i$ ). The later cannot be ignored in seismic zone with strong activity for intensity less than VII and the evaluated period is long, like 50 years or 100 years. The general seismic hazard assessment assumes that the occurrence of earthquake is independent each other, therefore a solution is that the exceeding probability in a short time period $t$ can be firstly calculated from the hazard in long period $T$ as follows.

$$
P_{t}(I \geq i)=1-\left[1-P_{T}(I \geq i)\right]^{\frac{t}{T}}
$$

Obviously, $P(I=i$ and $I>i)$ can be ignored when the period is short enough. In general, one month is short enough for a region with generic seismic 
activity; it should be shorten to days for region with high activity. By this way, $P_{\mathrm{t}}(I=i)$ can be calculated by eq. (5).

$$
P_{t}(I=i)=P_{t}(I \geq i)-P_{t}(I \geq i+1)
$$

The occurring probability of intensity $I$ in long time period $T$, can be obtained in reverse of eq. (4).

$$
P_{T}(I=i)=1-\left[1-P_{t}(I=i)\right]^{\frac{T}{t}}
$$

The result of the case study is improved as shown in Table 2. One can see from the table that $\mathrm{P}(\mathrm{I}=\mathrm{i})$ is now monotone decreasing, and the probabilities in Table 1 are underestimated very much for intensity III and IV, also underestimated for intensity V, even VI. The similar underestimation may happen for higher intensity in region with high seismicity.

Table 2: The occurring probability of low intensity in 50 years.

\begin{tabular}{|c|c|c|c|c|}
\hline Intensity & III & IV & V & VI \\
\hline$P_{50}(I=i)$ & 0.7899 & 0.5277 & 0.2404 & 0.0535 \\
\hline
\end{tabular}

\section{Seismic hazard overestimation at high intensity range}

In general, high intensity area is not very large, since the fast attenuation at epicentre area. Following is a set of intensity attenuation relationships for North China.

$$
\begin{array}{cc}
I=6.046+1.480 M-4.792 \log \left(R_{a}+25\right), & \sigma_{a}=0.49 \\
I=2.617+1.435 M-3.318 \log \left(R_{b}+7\right), & \sigma_{b}=0.56
\end{array}
$$

where $I$ is intensity, are distances along major and minor axes respectively, $\sigma_{a}$ and $\sigma_{b}$ are regression variances of the two formulas, $M$ is magnitude. For $M=6,7$, 8 and $I=$ VIII, IX, X, $R_{a}, R_{b}$ and the areas of the ellipses corresponding to them can be calculated, and listed in Table 3 .

Table 3: $\quad R_{a}, R_{b}$ and the corresponding areas for given $M$ and $I$.

\begin{tabular}{|c|c|c|c|}
\hline $\begin{array}{c}\text { Intensity } \\
\text { Magnitude }\end{array}$ & VIII & IX & X \\
\hline 6 & $2.9 / 2.4 / 22$ & - & - \\
\hline 7 & $31.8 / 18.4 / 1837$ & $10.1 / 5.7 / 181$ & - \\
\hline 8 & $90.6 / 61.8 / 17582$ & $46.5 / 27.4 / 3997$ & $19.2 / 10.2 / 614$ \\
\hline
\end{tabular}


There are three numbers in each grid, the left is for $R_{a}$ in $\mathrm{km}$, the middle is for $R_{b}$ in $\mathrm{km}$, and the right is for the area in $\mathrm{km}^{2}$.

The area of the whole city in above case study is $22161 \mathrm{~km}^{2}$, none of high intensity areas in the table reaches this value, i.e. never cover the whole city, even intensity VIII from an earthquake with very infrequent magnitude 8 . In conclusion, $P(I)$ in eq. (2) cannot be adopted in risk assessment for the occurring probability of $I$ to the whole city, otherwise the expected loss must be overestimated. The authors believe a solution is scenario earthquake method.

\section{A hazard expression - scenario earthquake}

Exceeding probability, hazard curve are not familiar to public, not only the original people, but also engineers, planners and decision makers. To express seismic hazard clearly to public, scenario earthquake has been adopted since 1990s. It is consistent with the regional seismic environment and is determined from the regional attenuation relationship of ground motion. By means of the procedure developed by the authors, the scenario earthquake can cause the same intensity with the intensity on the hazard curve with given exceeding probability, with a magnitude less than the upper bound magnitude of the potential source area with most contribution to the probability, and a distance comparative with the potential source area.

The potential source areas in the case study are shown in fig.1.

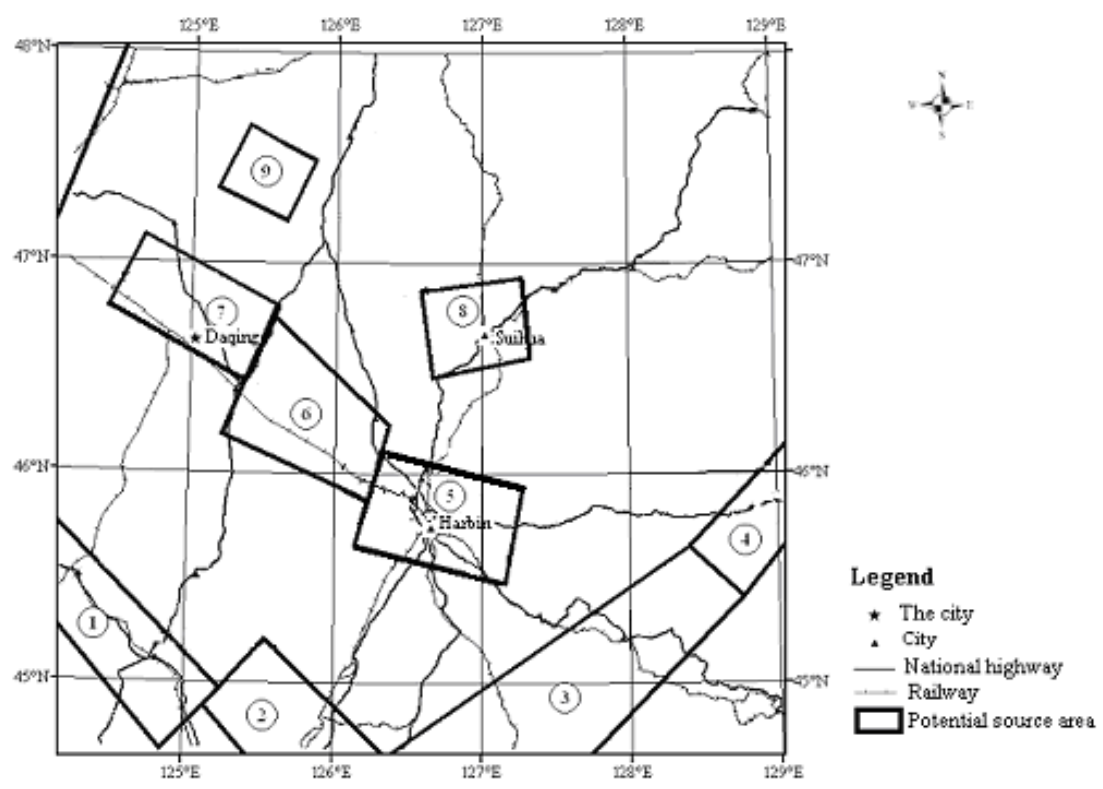

Figure 1: Potential source areas and scenario earthquake of the case study. 
GIS based systems for damage evaluation are developed for many cities and regions worldwide. The system is a powerful tool to perform spatial analysis and mapping of losses due to a scenario earthquake. The damaged areas of buildings, damaged length of highways, bridges or pipelines, damaged number of electric power or communicate facilities in 5 damage states from scenario earthquake can be assessed very fast. Damage results of the case study from scenario earthquakes with magnitudes 6 and 5 respectively corresponding occurring probabilities 0.005 and 0.0000426 in 50 years, are shown in fig. 2 and fig. 3. In each figure, (a) is for building damage, (b) for road network damage, (c) for electric power system damage, and (d) for water supply system, respectively.

From the figures, one can see that the highest intensities are VII and VIII, but the areas with these intensities are very limited. Furthermore, the system can estimate the gross loss, death and injuries, and their spatial distribution quickly by spatial operating capacity of GIS. The results of this case are listed in table 4.

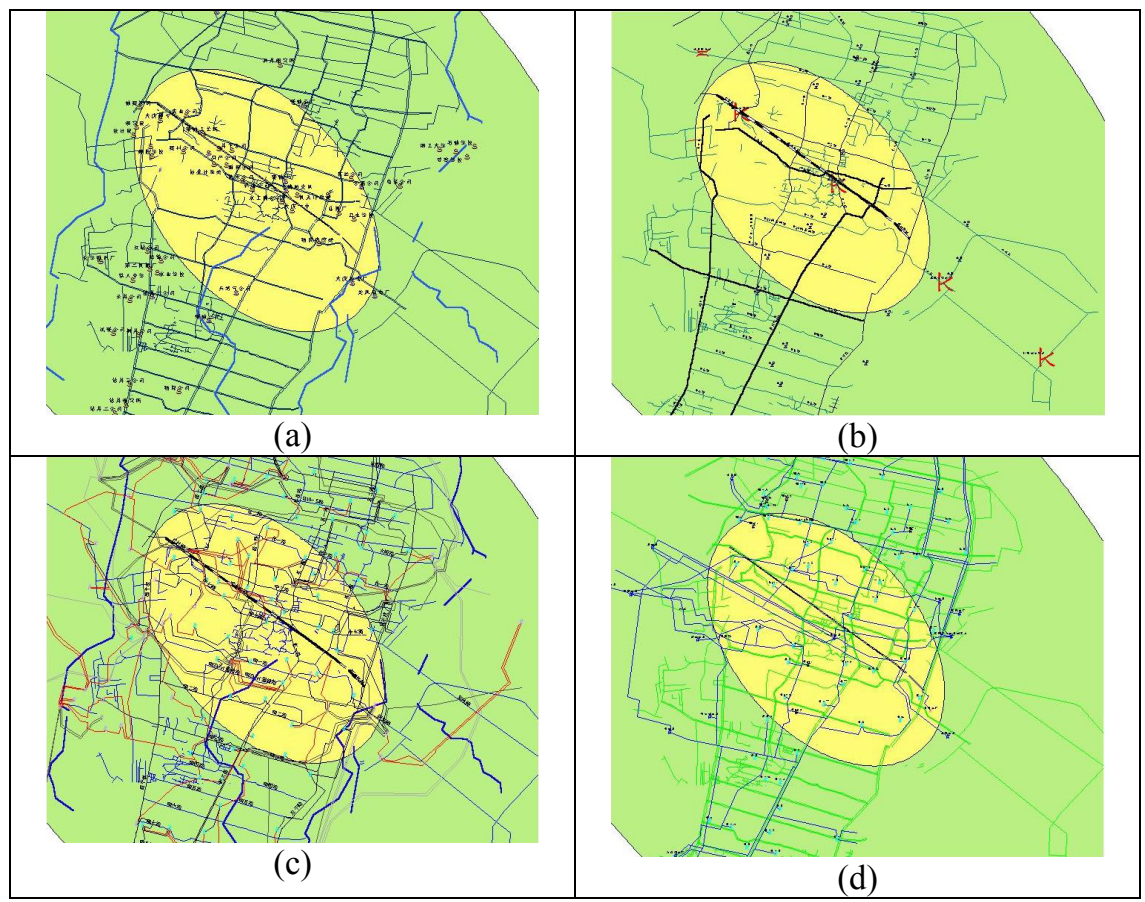

Figure 2: Damage caused by an earthquake with magnitude 5 in the case study.

Table 4: $\quad$ Gross loss, death, injuries and homeless.

\begin{tabular}{|c|c|c|c|c|}
\hline Scenario E.Q. & Loss (Million RMB) & Death & Injuries & Homeless \\
\hline 5.0 & 48.1 & 0 & 0 & 509 \\
\hline 6.0 & 1124.8 & 101 & 404 & 94709 \\
\hline
\end{tabular}




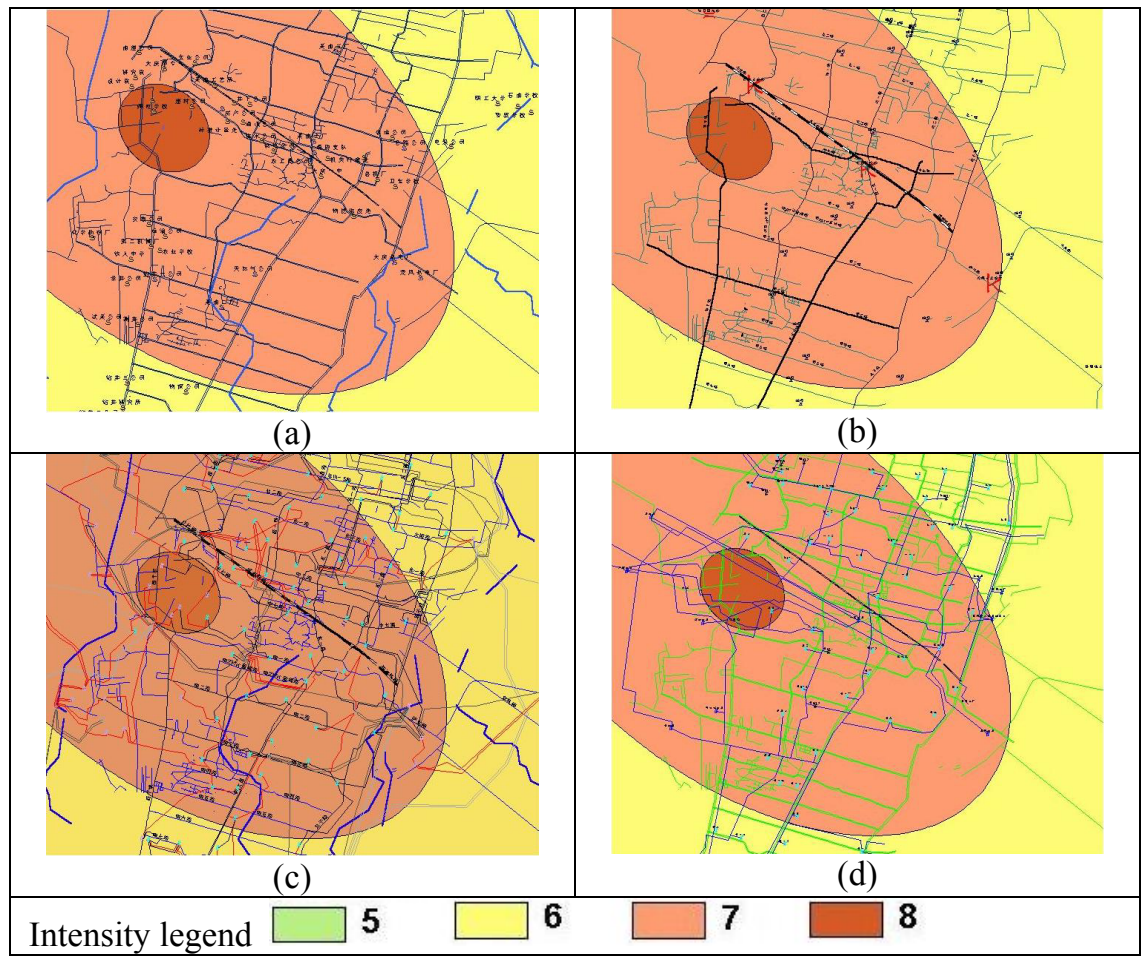

Figure 3: Damage caused by an earthquake with magnitude 6 in the case study.

\section{Conclusions}

Two problems in seismic hazard expression are pointed out in this paper for risk assessment. One at low intensity range corrected by formula (4) to (6). Another is solved by scenario earthquake method. The latter must be assisted by a GIS base system. For example, the damage estimation of buildings, road network system, electric power system, water supply system are shown for a case study, and then the gross loss, death, injuries and homeless are also listed for demonstration.

\section{Acknowledgements}

This research is supported partly by the Earthquake Science Foundation under Contract No.606027, the Heilongjiang Natural Science Foundation under Contract No.G2005-13, and by the Science Foundation (No. TDXX-0504) from the Key Lab. on Information Science and Engineering of the Chinese Railway Ministry. 


\section{References}

[1] Franz Sauter, EERI Committee on Seismic Risk, Glossary of terms for probabilistic seismic-risk and hazard analysis. Earthquake Spectra, 1, pp.33-40, 1984.

[2] Anton Zaicenco and Vasile Alkaz, Urban Seismic Risk Studies with Utilization of GIS. Presentation on NATO Advanced Research Workshop, 2005 .

[3] B. Tucker, et al., The Quito, Ecuador, earthquake risk management project: An evaluation, Proc. of $5^{\text {th }}$ Int. conf. on seismic zonation, pp1781804, 1995, Nice.

[4] R. K. McGuire, Scenario earthquake for loss studies based on risk analysis, Proc. of $5^{\text {th }}$ Int. conf. on seismic zonation, pp1325-1333, 1995, Nice.

[5] M. Erdik and J. Swift-Avci, Development of earthquake hazard and damage scenarios, Proc. of $5^{\text {th }}$ Int. conf. on seismic zonation, pp21532165, 1995, Nice.

[6] L. Xie, X. Tao et al. A GIS based earthquake losses assessment and emergency response system for Daqing oil field, Proc. of $12^{\text {th }}$ World Conf. on earthquake engineering, Paper No. 0091, 2000, Auckland. 